\title{
Variation in the relative importance of sublethal effects of predators and competitors on growth of a temperate reef fish
}

\author{
Mark A. Steele*, Graham E. Forrester \\ Department of Biological Sciences, University of Rhode Island, 100 Flagg Road, Kingston, Rhode Island 02881, USA
}

\begin{abstract}
Sublethal effects of predators on the growth of their prey have been little studied in marine systems and consequently their importance relative to other factors is poorly known. Using a set of field experiments conducted on small artificial patch reefs, we measured the relative importance of the effects of predators and conspecific competitors on the growth of a temperate reef fish, the blackeye goby Coryphopterus nicholsii, and we measured how the importance of the 2 processes varied over time. We found that predators and competitors reduced the growth of the gobies at some times, but not others, and that the relative importance of the 2 processes varied among time periods. Moreover, the importance of the 2 processes varied as a function of body size, with large, fast-growing individuals suffering relatively more from the effects of predators than small, slow-growing individuals, which felt the effects of competition more keenly. Competition increased the variation (CV) in growth rates within populations, but exposure to predators had no effect on growth variability. The strength of both the competitive and predatory effects on growth rates declined from summer to winter, but the effect of competition on growth variability did not change appreciably over time. The decline in the effects of competitors and predators on growth rates corresponded to predictable seasonal declines in water temperature and predator abundance. The relative importance of the sublethal effects of predators was greatest during the summer, when predators were most abundant. This study highlights the potential importance of sublethal effects of predators in marine systems and it suggests that the relative importance of predatory and competitive effects may vary in predictable seasonal and ontogenetic ways.
\end{abstract}

KEY WORDS: Asymmetric competition · Predators · Sublethal effects · Growth · Relative importance · Reef fish · Coryphopterus nicholsii

\section{INTRODUCTION}

In addition to the direct negative effect of predation on prey population density, the mere presence of predators may reduce the growth of individuals within prey populations (e.g. Werner et al. 1983, Fraser \& Gilliam 1992, Nakaoka 2000). Such sublethal effects can have important ramifications for population structure and dynamics (Werner \& Gilliam 1984, McPeek \& Peckarsky 1998). For example, by influencing body size, variation in growth rates can translate to variation in the rates of mortality, maturity, and fecundity

\footnotetext{
*E-mail: steele@uri.edu
}

(Werner \& Gilliam 1984). Sublethal effects of predators on growth of their prey are well known in freshwater systems (e.g. Werner et al. 1983, Semlitsch 1987, Skelly \& Werner 1990, Fraser \& Gilliam 1992, Peckarsky et al. 1993, Scrimgeour \& Culp 1994), but they have seldom been studied in marine systems (for rare examples, see Connell 1998, Steele 1998, Nakaoka 2000). Consequently, the relative importance (sensu Welden \& Slauson 1986) of sublethal effects of predators in marine systems is poorly known.

Here, we evaluate the importance of sublethal effects of predators relative to those of conspecific competitors, which are well known to influence the growth rates of marine animals (e.g. Peterman 1984, 
Jones 1987, 1991, Levitan 1988, Stoner 1989). Since population densities of predators and conspecifics typically vary in space and time (Krebs 1994), it is not surprising that their effects do too (e.g. Dayton 1971, Menge 1983, Fairweather et al. 1984, Bertness 1989, Vincent et al. 1994). In particular, there can be strong seasonal variation in the effects of predators and competitors (e.g. Underwood 1984, Wissinger 1989, Micheli 1997, Sano 1997, Beal et al. 2001), but how such seasonal variation influences the relative importance of the 2 processes is poorly known. For example, it is not known whether the 2 processes typically covary, such that competition is intense when predatory effects are intense, or whether the intensity of each process varies independently.

In this study, we use a reef fish to explore temporal variation in the relative importance of the sublethal effects of predators and conspecific competitors, and we relate this to predictable seasonal changes. Reef fishes have long been used as model organisms in ecological studies, yet the relative importance of the processes that affect them is still not well known and has only recently received much attention (e.g. Forrester 1990, Hixon \& Carr 1997, Steele 1997, Schmitt \& Holbrook 1999, Schmitt et al. 1999, Shima 1999). Specifically, the relative importance of the sublethal effects of predators and conspecific competitors in reef fishes is almost completely unknown (but see Steele 1998), and no effort has yet been made to determine whether the relative importance of these 2 processes varies over time. Here we test the hypothesis that the relative importance of sublethal effects of predators and competitors varies with predictable seasonal changes in the biotic and abiotic environment.

\section{MATERIALS AND METHODS}

Study system. We studied the blackeye goby Coryphopterus nicholsii (family Gobiidae), a small (<100 mm standard length [SL]) reef fish that is common along the Pacific coast of North America (Miller \& Lea 1976). This species lives in areas of mixed sand and rock rubble, where it spends most of its time resting on the substrate. It forages for benthic invertebrates found in and on the substrate and also darts into the water column to capture zooplankton. Blackeye gobies seldom move more than about $0.5 \mathrm{~m}$ away from rocky substrate because they use associated crevices and excavated burrows to hide from predators. Juveniles settle from the plankton at sizes ranging from 15 to $25 \mathrm{~mm}$ SL (Steele \& Forrester unpubl. data) and they grow rapidly to reach sexual maturity within a few months (Steele unpubl. data) at a size of about 45 to 50 mm SL (Wiley 1973, Cole 1983). Blackeye gobies are protogynous hermaphrodites and, consequently, most large adults are male, whereas smaller adults are usually female (Cole 1983, Breitburg 1987). The species is territorial, but territories overlap, the greatest overlap occuring between individuals that differ considerably in size (Cole 1984). Small (<25 mm SL), recently settled juveniles are not territorial and are ignored by larger, older individuals that maintain territories $<1.0 \mathrm{~m}^{2}$ (Cole 1984, M. Steele pers. obs.). Social organization and territory size is based upon dominance relationships that are determined largely by body size (Cole 1982, Breitburg 1987).

We conducted our study at Santa Catalina Island $\left(33^{\circ} 27^{\prime} \mathrm{N}, 118^{\circ} 29^{\prime} \mathrm{W}\right), 35 \mathrm{~km}$ off the coast of southern California. Here the main predator of the blackeye goby is the kelp bass Paralabrax clathratus (family Serranidae), but the barred sand bass $P$. nebulifer, an important predator at coastal sites where it is abundant (Wiley 1973), is also present in low numbers. The combined impact of these predators on survival of blackeye gobies is quite variable, with some studies finding little or no effect of predators (Steele 1998, Forrester \& Steele 2000) and others finding large effects (Steele 1996, 1999, Forrester \& Steele 2000).

Experiments. We explored the relative importance of sublethal effects of predators and intraspecific competition on growth of blackeye gobies over 3 one-month periods in 2 experiments that were identical in design. The 3 periods spanned the summer and early winter and so encompassed predictable seasonal changes in water temperature and predator abundance (M. Steele pers. obs.). We estimated variation in predator abundance among the 3 mo of the study by counting the number of kelp and barred sand bass within $1 \mathrm{~m}$ of each of the artificial reefs on which we established populations of gobies. These counts provided a useful index of predator abundance but they could not provide an accurate measure of predator density because these predators are very mobile and tend to aggregate to divers, thus inflating density estimates. The predator counts were made 1 to 10 times during each month of the study. We estimated seasonal changes in water temperature from data obtained from the National Oceanic and Atmospheric Administration's National Data Buoy Center from the automated Catalina Ridge weather buoy (\#46025; located at $33^{\circ} 44^{\prime} 48^{\prime \prime} \mathrm{N}$, $\left.119^{\circ} 04^{\prime} 06^{\prime \prime} \mathrm{W}\right)$, which records water temperature hourly at $0.6 \mathrm{~m}$ depth. This buoy is located about $60 \mathrm{~km}$ from our study site, so we do not expect the temperatures recorded there to be identical to those at our study site, but they should reflect the seasonal trends that we were interested in.

In our experiments, we manipulated concurrently the density of blackeye gobies and the presence of predators on a set of 16 artificial reefs in Big Fisherman 
Cove (see Steele 1997 for a map of the site). Half of the reefs were exposed to predators and the other half were not, and on each of the 2 sets of reefs the same range of densities of gobies was stocked: 2 to 15 subadult and adult gobies (35 to $50 \mathrm{~mm}$ SL) per $1 \mathrm{~m}^{2}$ reef. These densities spanned and slightly exceeded those encountered in nature for this size class of gobies. Exposure to predators was manipulated with cages: reefs free of predators had cages around them and reefs exposed to predators did not. A previous study (Steele 1996) demonstrated that the cages used in the present study have no unintended effects on blackeye gobies. In particular, the cages do not enhance the growth of blackeye gobies - an artifact that could be mistaken for a sublethal effect of predators. The cages were $1 \times 1 \times 0.67 \mathrm{~m}$ high and constructed of $18 \mathrm{~mm}$ mesh, rigid, black, plastic netting on PVC pipe frames. The mesh was large enough for the gobies to pass through easily and they did so regularly. Consequently, the gobies in the 'predator-free' treatment were sometimes exposed to predators, although they seldom ventured far from the cages and they could always retreat to them for safety.

We assigned individual gobies to treatments such that the mean size and variation in size (coefficient of variation, $\mathrm{CV}$ ) of fish at the start of each experiment did not vary systematically with conspecific density or predator treatment $(p>0.30$ for both main effects and their interaction in analyses of covariance [ANCOVAs] including the factor 'predator treatment' and the covariate 'conspecific density'). Furthermore, at the end of the experiments the mean and CV of starting sizes of gobies that had survived through each experiment did not differ among treatments (all p's > 0.2 in ANCOVAs as above) because predation, and mortality from all sources, were independent of goby size during each month of the study (p's > 0.6 in KolmogorovSmirnov tests comparing the starting sizes of gobies that died vs survived [restricted to reefs exposed to predators for tests of size-selective predation] in each month of the experiments).

The 16 experimental reefs were built in a rectangular grid pattern $(8 \times 2$ reefs $)$ on a sand plain with adjacent reefs separated by $10 \mathrm{~m}$ to discourage movement of gobies among reefs. The reefs were constructed of a standard size distribution of rocks (5 to $30 \mathrm{~cm}$ long) translocated from a local reef. We injected a $1 \times 2.5 \mathrm{~mm}$ tag with a unique, 3 digit, alphanumeric code (visual implant tag; Northwest Marine Technology, Shaw Island, WA) under the skin of each fish. These tags were visible through the skin of the fish and they allowed us to (1) measure the growth of each fish by simply measuring it at the beginning and the end of each month-long period, and (2) detect migration among reefs. Only 5 out of 184 gobies moved among reefs; these movements occurred with the first few days of the start of the experiments and the migrants then remained on the reef they had moved to. Therefore, we considered those 5 fish to be residents on the reefs they moved to and included their growth in the estimate of growth on those reefs.

Our 2 experiments were conducted in 1996: the first (Expt 1) ran during July and August (32 d) and the second (Expt 2) during October to December. We divided Expt 2 into 2 periods (roughly 1 mo each: 32 and $27 \mathrm{~d}$, respectively). At the end of each of the 3 one-month periods, divers using handnets and the anesthetic quinaldine captured each tagged goby and measured it. At the end of the first month of Expt 2, after being captured and measured underwater, the gobies from each reef were allowed to recover from anesthesia for 10 to $20 \mathrm{~min}$ in a clear glass bottle (2 1) placed next to their reef and then released back onto it. A month later, those individuals still remaining (93\% were still present) were captured and measured again.

The 2 experiments differed slightly. During Expt 1, the reefs were composed of fewer and smaller rocks (64 vs 68 rocks, approximately 40 vs 601 in total volume) and therefore they provided somewhat less shelter. Also in this experiment we used slightly smaller gobies (35-45 vs 40-50 mm SL), which reflected the field population at that time. The last important difference is that we protected the 8 predator-exposed reefs in Expt 2 with cages for the first $24 \mathrm{~h}$ after the gobies were stocked to protect them from predators while they became familiar with the reefs, whereas the 8 predator-exposed reefs in Expt 1 were not protected from predators at the start of that experiment. The gobies on these unprotected reefs suffered extensive (sizeindependent) mortality, most within the first $24 \mathrm{~h}$ of that experiment $(65 \%$ died within $24 \mathrm{~h}$ and $83 \%$ died over the entire month), and consequently, the number of replicates with surviving gobies ( $\mathrm{n}=3$ instead of 8 ) and the range of goby densities (1.0-6.6 vs $2.0-14.0$ reef $^{-1} \mathrm{~d}^{-1}$ ) were lower in the predator-exposed than the predator-free treatment. Hence, our test for densitydependent growth on reefs exposed to predators in Expt 1 was compromised.

In each month, the gobies on every reef were surveyed visually on several occasions and we used these counts, along with the numbers of gobies captured at the end of each month, to calculate the time-averaged density on each reef in each month. Linear interpolation was used to estimate densities between censuses. Except on the reefs exposed to predators in Expt 1, the density treatments were well maintained because there was no detectable predation during Expt 2 and mortality was slight and density-independent (mortality $=13,8.3,8.7,7.0$, $7.7 \%$ on predator-free reefs in Expt 1, predator-free reefs in the first month of Expt 2, predator-exposed reefs in the 
first month of Expt 2, predator-free reefs in the second month of Expt 2, and predator-exposed reefs in the second month of Expt 2, respectively; Forrester \& Steele 2000). Because some fish were lost from the reefs, the time-averaged density estimates were more accurate measures of the actual densities experienced by the gobies than the densities stocked, so we used them in our tests for density-dependent growth.

Statistical analyses. Treating reefs as replicates, we used 4 response variables to explore the effects of predators and competitors on growth of blackeye gobies. These variables were (1) mean growth, (2) variation in growth (coefficient of variation, CV), (3) minimum growth (growth of the slowest-growing fish on each reef), and (4) maximum growth (growth of the fastest-growing fish on each reef). We examined minimum and maximum growth to evaluate the symmetry of effects of predators and competitors.

The experiments were designed to be analyzed with analysis of covariance (ANCOVA), with 'predator treatment' a categorical variable and 'conspecific density' the covariate. We used this approach for Expt 2, but unfortunately, it was inappropriate for Expt 1 as it was not possible to calculate a reliable estimate of the strength of competition in the presence of predators due to the low replication and range of densities on the predator-exposed reefs. Therefore, we used a simple linear regression to test for competition only on the 8 reefs free of predators in Expt 1. We tested for an effect of predators during Expt 1 with a $t$-test comparing the 3 reefs exposed to predators to the 8 reefs protected from them.

For Expt 2, we used ANCOVA with 2 categorical variables, 'predator treatment' and 'month' (first or second), and the continuous variable 'conspecific density'. In cases where these analyses revealed that either the effects of predators or conspecifics differed between the 2 mo of the experiment (i.e. significant interactions), we used separate ANCOVAs for each of the 2 mo of the experiment to elucidate the cause of the interactions. ANCOVA was also used to explore the effects of body size on individual growth rates. This is described in more detail in 'Results'. In all ANCOVAs, non-significant $(p>0.05)$ interactions between categorical factors and covariates, indicating homogeneity of slopes, were eliminated from the statistical models before testing the main effects and lower-level interactions (Wilkinson et al. 1992).

We measured the relative importance of the sublethal effects of predators and conspecific competitors by comparing the magnitude of effects attributable to each factor in each month-long experimental period. This is described in detail in the next section. We compared the abundance of predators (kelp and barred sand bass) among the 3 study months with the nonparametric Kruskal-Wallis test because the data were not normally distributed. This analysis compared the average number of bass seen near the reefs among the 3 mo of the study using the experimental reefs as replicates. We compared water temperature among the 3 mo of the study with one-way ANOVA, using each hourly measurement as a replicate. For all parametric tests, we visually evaluated the assumption of normality with normal-probability plots of residuals and homoscedasticity with plots of residuals vs estimated values. For categorical data, we further evaluated the assumption of homoscedasticity with Cochran's C-test. There were no significant violations of the parametric assumptions.

\section{RESULTS}

The effects of predators and competitors differed considerably among the 3 months of the study and among response variables. In Expt 1, intraspecific competition

Table 1. Summary of tests for effects of competitors and predators on growth rates of blackeye gobies in Expt 1. Competition was evaluated only on reefs protected from predators, using linear regression. Effects of predators were evaluated with $t$-tests comparing 8 reefs free of predators with 3 exposed to predators. Tests were made with 4 response variables: mean growth, minimum growth (growth of the slowest growing fish on each reef), maximum growth (growth of the fastest growing fish on each reef), and the coefficient of variation (CV) of growth. Each reef was a replicate. Two of the 3 reefs exposed to predators had only 1 goby on them at the end of the experiment, so no meaningful estimate of the CV or test for influences of predators on it could be made

\begin{tabular}{|c|c|c|c|c|c|c|c|c|c|c|c|}
\hline \multirow{2}{*}{\multicolumn{6}{|c|}{$\begin{array}{l}\text { Mean growth }-\quad-\text { Minimum growth }- \\
\text { Competition (linear regression; } \mathbf{n}=\mathbf{8} \text { ) }\end{array}$}} & \multicolumn{3}{|c|}{ Maximum growth } & \multicolumn{3}{|c|}{$\longrightarrow \mathrm{CV}-$} \\
\hline & & & & & & & & & & & \\
\hline Slope & $\mathrm{r}^{2}$ & $\mathrm{p}$ & Slope & $\mathrm{r}^{2}$ & $\mathrm{p}$ & Slope & $\mathrm{r}^{2}$ & $\mathrm{p}$ & Slope & $\mathrm{r}^{2}$ & $\mathrm{p}$ \\
\hline-0.0078 & 0.72 & 0.008 & -0.0126 & 0.72 & 0.008 & -0.0036 & 0.55 & 0.036 & 0.010 & 0.44 & 0.075 \\
\hline \multicolumn{12}{|c|}{ Predation ( $t$-test) } \\
\hline$t$ & df & $\mathrm{p}$ & $t$ & $\mathrm{df}$ & $\mathrm{p}$ & $t$ & df & $\mathrm{p}$ & $t$ & $\mathrm{df}$ & $\mathrm{p}$ \\
\hline-3.42 & 9 & 0.008 & -2.41 & 9 & 0.039 & -3.30 & 9 & 0.009 & \multicolumn{3}{|c|}{ Insufficient data for test } \\
\hline
\end{tabular}


in the absence of predators caused mean, minimum, and maximum growth to decline with density and tended to cause variation in growth to increase with density (Table 1, Figs. 1a \& 2a,b). Competition appeared to be asymmetric, since minimum growth was affected more strongly (i.e. steeper slope) by population density than was maximum growth (Fig. 2a, Table 1). We could not determine whether competition occurred in the presence of predators in Expt 1 due to low replication and a limited range of densities. By comparing the 3 predator-exposed reefs that had surviving gobies at the end of the experiment to the 8 predator-free reefs, we found that the presence of predators reduced mean growth by $35 \%$, minimum growth by $37 \%$, and maximum growth by $34 \%$ (Tables 1 \& 2, Figs. 1a \& 2a). We could not determine whether predators influenced growth variability (CV) during this experiment because only one reef exposed to predators had more than one fish remaining at the end, making it impossible to calculate the error of the estimate of CV.

In Expt 2, the effects of predators and competitors generally differed between the 2 months of the experiment. The main exception was that in both months, predators had no effect on growth variability $(\mathrm{CV})$, whereas competitors did, causing variability to increase with population density (Tables $2 \& 3$, Fig. 2d,f). The effects of predators and conspecifics on mean growth differed between the 2 months, indicated by significant 'predator treatment $\times$ month' and 'conspecific density $\times$ month' interactions (Table 3 ). These interactions occurred because predators and competitors both had significant effects on growth in the first month of Expt 2, but not in the second (Tables $2 \& 3$, Fig. 1b,c).

The effects of predators on minimum and maximum growth in Expt 2 generally mirrored those on mean growth, with significant differences in the effects of predators in the 2 mo (significant 'predator treatment $x$ month' interactions for both: Table 3). For both of these measures of growth, predators tended to slow growth in the first month and have no effect in the second month (Tables 2 \& 3, Fig. 2c,e). Predators reduced mean growth by $10 \%$, minimum growth by $11 \%$, and maximum growth by $7 \%$ in the first month and caused non-significant increases in growth of 8 to $16 \%$ in the second month (Table 2, Fig. 3c,e).

In Expt 2, the effects of conspecific competitors differed between fast and slow growing gobies (i.e. minimum and maximum growth; Table 3, Fig. 2c, e), indicating that competition was asymmetric. Minimum growth declined significantly with density in both months of Expt 2 and the strength of competitive effects on minimum growth did not differ between the 2 mo (i.e. non-significant 'conspecific density $\times$ month' interaction; Table 3, Fig. 3c,e). In contrast, the effects
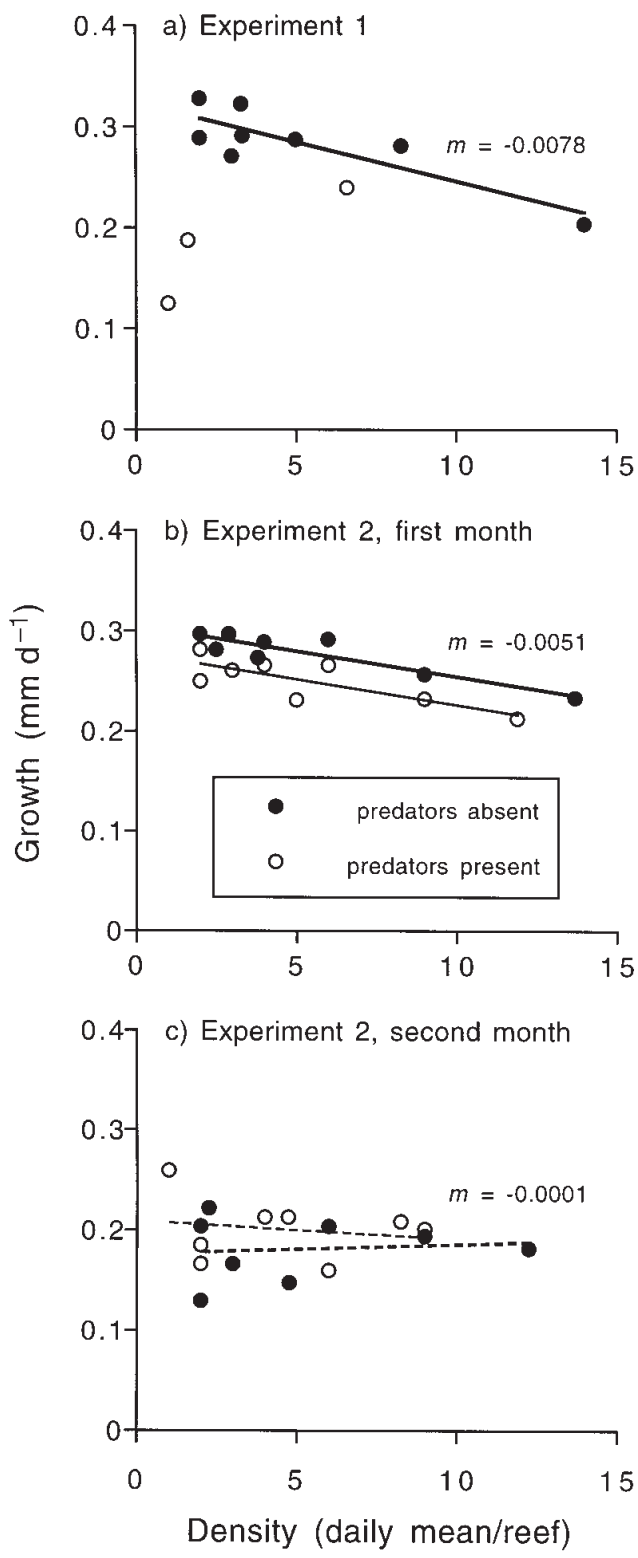

Fig. 1. Relationship between mean growth of blackeye gobies and density of conspecifics on reefs free of predators and reefs exposed to predators. Relationships are shown for 3 onemonth-long periods in 2 experiments. Solid lines indicate statistically significant relationships (Tables $1 \& 3$ ) and $m$ is the slope, pooled from both predator treatments in Expt 2 since slopes did not differ between predator treatments. Each point represents the mean growth rate of all individuals on one reef

of conspecific density on maximum growth differed significantly between months, with no effect of population density in the first month and a positive effect in the second month (Table 3, Fig. 3c,e). By some mechanism, high population densities enhanced growth of the fastest growing fish. However, in neither month did predators affect the strength of competition, i.e. there were no 'predator treatment $\times$ conspecific density' interactions (Table 3, Figs. 1b,c \& 2c,e). Moreover, 
Minimum \& Maximum Growth

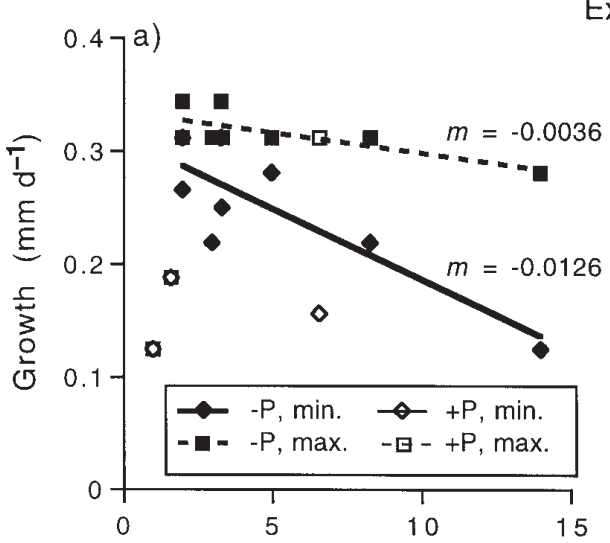

Variation in Growth (CV)

Experiment 1

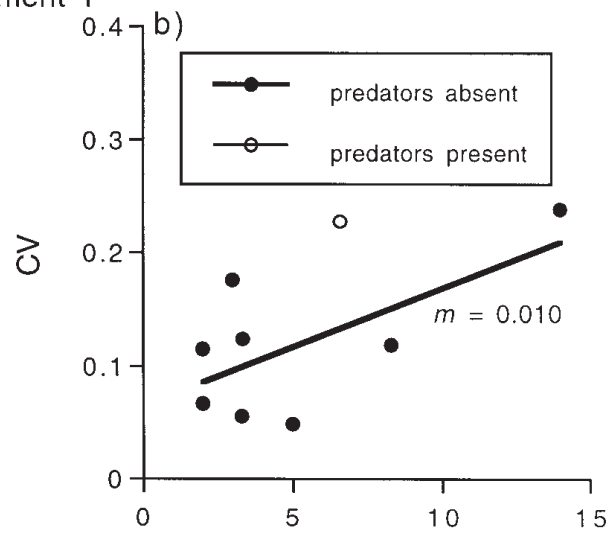

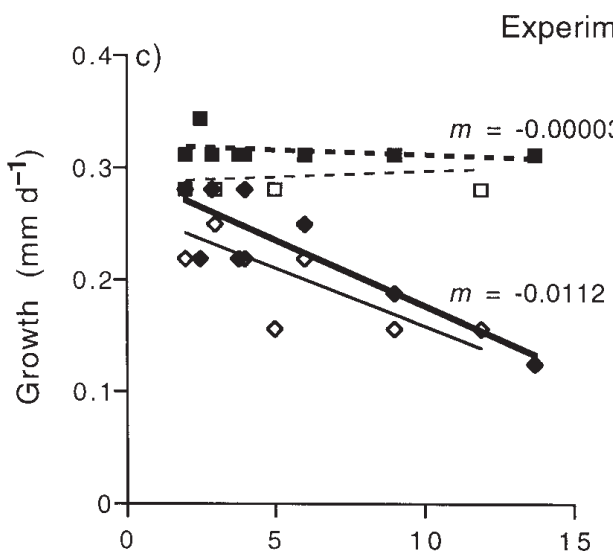

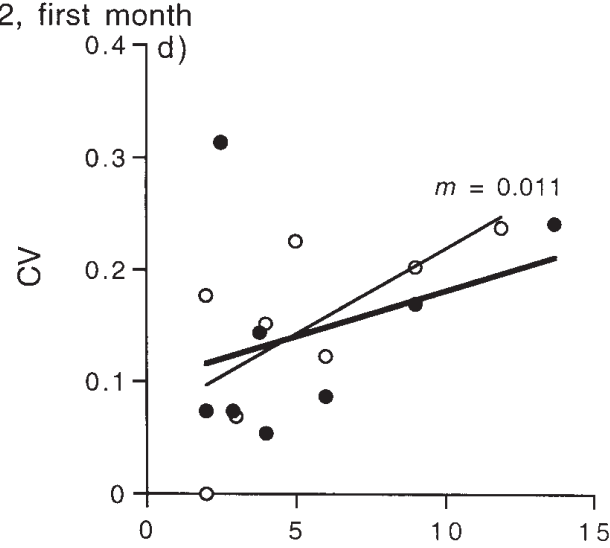

Experiment 2, second month
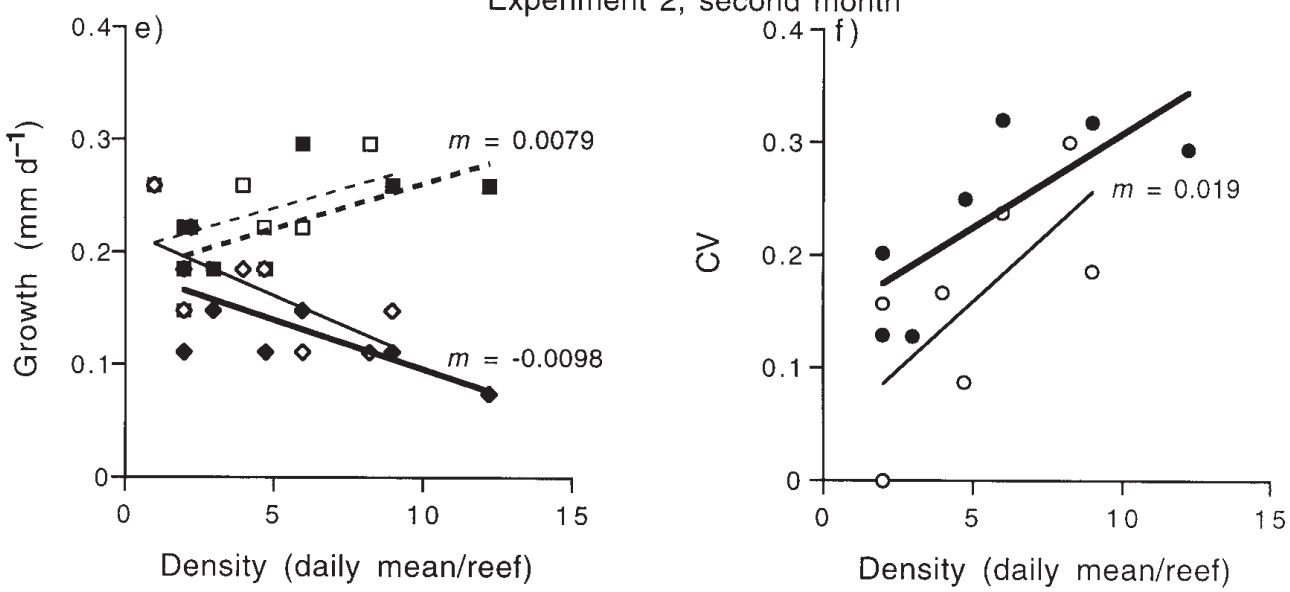

Fig. 2. Relationships between minimum growth, maximum growth, and variability in growth (coefficient of variation, CV) and density of conspecifics on reefs free of predators and exposed to predators. $-\mathrm{P}=$ predator-free reefs, $+\mathrm{P}=$ predator-exposed reefs, min. = minimum growth, max. = maximum growth. For statistics, see Tables $1,2 \& 3$. The slope, $m$, is pooled from both predator treatments in Expt 2 since slopes did not differ between predator treatments (Table 3)

since there was no detectable predation during this experiment (Forrester \& Steele 2000), predators did not reduce the intensity of competition by reducing population densities.
Growth of individual gobies was a complex function of body size. Within each month-long period, large fish generally grew more rapidly than smaller fish (Fig. 3). Maximum growers were larger than minimum growers 
Table 2. Growth and variability in growth in the presence and absence of predators. $+\mathrm{P}=$ predators present, $-\mathrm{P}=$ predators absent. Data are means and $(1 \mathrm{SE})$; least squares adjusted means and pooled SE are shown for Expt 2 . Significant differences (Tables 1 \& 3) are denoted by an asterisk

\begin{tabular}{|c|c|c|c|c|c|c|c|c|}
\hline & \multicolumn{2}{|c|}{ Mean growth } & \multicolumn{2}{|c|}{ Minimum growth } & \multicolumn{2}{|c|}{ Maximum growth } & \multicolumn{2}{|c|}{$\mathrm{CV}$} \\
\hline & $-\mathrm{P}$ & $+\mathrm{P}$ & $-\mathrm{P}$ & $+\mathrm{P}$ & $-\mathrm{P}$ & $+\mathrm{P}$ & $-\mathrm{P}$ & $+\mathrm{P}$ \\
\hline Expt 1 & $\begin{array}{c}0.284 \\
(0.038) \\
\mathrm{n}=3\end{array}$ & $\begin{array}{c}0.184^{*} \\
(0.057) \\
n=8\end{array}$ & $\begin{array}{c}0.248 \\
(0.061) \\
\mathrm{n}=3\end{array}$ & $\begin{array}{c}0.156^{*} \\
(0.032) \\
n=8\end{array}$ & $\begin{array}{c}0.316 \\
(0.020) \\
\mathrm{n}=3\end{array}$ & $\begin{array}{c}0.208^{*} \\
(0.095) \\
\mathrm{n}=8\end{array}$ & $\begin{array}{c}0.228 \\
- \\
\mathrm{n}=1\end{array}$ & $\begin{array}{c}0.118 \\
(0.023) \\
n=8\end{array}$ \\
\hline $\begin{array}{l}\text { Expt 2, } \\
\text { 1st month }\end{array}$ & $\begin{array}{c}0.278 \\
(0.004) \\
\mathrm{n}=8\end{array}$ & $\begin{array}{c}0.250^{*} \\
(0.004) \\
\mathrm{n}=8\end{array}$ & $\begin{array}{c}0.231 \\
(0.011) \\
\mathrm{n}=8\end{array}$ & $\begin{array}{c}0.206 \\
(0.011) \\
\mathrm{n}=8\end{array}$ & $\begin{array}{c}0.316 \\
(0.005) \\
\mathrm{n}=8\end{array}$ & $\begin{array}{c}0.293^{*} \\
(0.005) \\
\mathrm{n}=8\end{array}$ & $\begin{array}{c}0.144 \\
(0.028) \\
n=8\end{array}$ & $\begin{array}{c}0.149 \\
(0.028) \\
n=8\end{array}$ \\
\hline $\begin{array}{l}\text { Expt 2, } \\
\text { 2nd month }\end{array}$ & $\begin{array}{c}0.181 \\
(0.011) \\
n=8\end{array}$ & $\begin{array}{c}0.201 \\
(0.011) \\
n=8\end{array}$ & $\begin{array}{c}0.141 \\
(0.013) \\
\mathrm{n}=8\end{array}$ & $\begin{array}{c}0.164 \\
(0.013) \\
n=8\end{array}$ & $\begin{array}{c}0.220 \\
(0.013) \\
n=8\end{array}$ & $\begin{array}{c}0.238 \\
(0.013) \\
\mathrm{n}=8\end{array}$ & $\begin{array}{c}0.230 \\
(0.025) \\
n=7\end{array}$ & $\begin{array}{c}0.166 \\
(0.025) \\
n=7\end{array}$ \\
\hline
\end{tabular}

in both months of Expt 2, but not in Expt 1 (paired $t$-tests, Expt 1: $t=0.65, \mathrm{df}=10, \mathrm{p}=0.5$; first month of Expt 2: $t=-3.41, \mathrm{df}=15, \mathrm{p}=0.004 ;$ and second month of Expt 2: $t=-2.34, \mathrm{df}=15$, and $\mathrm{p}=0.03$ ). The tendency for individual growth to increase with body size, however, varied with population density, as indicated by significant interactions between size and population density in ANCOVAs (Table 4). The tendency for larger fish to grow more rapidly than small fish was stronger in high-density than in low-density populations (Fig. 4), supporting the idea that size-based dom- inance hierarchies influenced growth rates in highdensity populations. Mean growth rates differed among the 3 mo of the study, being relatively high and similar in the first 2 mo $(0.257 \pm 0.019$ and $0.264 \pm$ $0.007 \mathrm{~mm} \mathrm{~d}^{-1}$ in months 1 and 2, respectively), and lower in the third month $\left(0.191 \pm 0.008 \mathrm{~mm} \mathrm{~d}^{-1}\right)$. The slower growth of the gobies in the third month of the study, however, cannot be explained entirely by differences in goby size among the 3 mo of the study. Even though growth in this species does decline with size over a wide range of size (Steele 1998) and gobies in

Table 3. Summary of results of analysis of covariance (ANCOVA) of Expt. 2 testing for effects of predators, conspecific density (the covariate), experimental period (month: first or second), and interactions between these main effects on measures of growth and growth variability (as in Table 1). Each reef was a replicate. Separate ANOVAs were calculated for each month of the experiment if there were significant interactions with 'month' in the overall analysis. In the second month, 2 reefs had only one goby on them at the end of the experiment, so no meaningful estimate of the CV could be made for those replicates. ${ }^{*}$ Non-significant ( $p>0.05$ ) interactions with the covariate were sequentially eliminated from the models before testing main effects and lowerlevel interactions (Wilkinson et al. 1992). Significant effects are shown in bold. p-values are not reported for main effects involved in interactions because these tests are meaningless (Underwood 1997). NA: not applicable

\begin{tabular}{|c|c|c|c|c|c|c|c|c|c|c|c|c|}
\hline \multirow[t]{2}{*}{ Source } & \multicolumn{3}{|c|}{ Mean growth } & \multicolumn{3}{|c|}{ Minimum growth } & \multicolumn{3}{|c|}{ Maximum growth } & \multicolumn{3}{|c|}{$\mathrm{CV}$} \\
\hline & df & F & $\mathrm{p}$ & df & $F$ & $\mathrm{p}$ & df & $F$ & $\mathrm{p}$ & df & $F$ & $\mathrm{p}$ \\
\hline \multicolumn{13}{|c|}{ Overall analyses of Expt 2} \\
\hline Predators (P) & 1,25 & 0.00 & NA & 1,27 & 0.01 & NA & 1,26 & 0.07 & NA & 1,25 & 1.26 & 0.27 \\
\hline Conspecifics (C) & 1,25 & 5.32 & NA & 1,27 & 37.80 & $<0.001$ & 1,26 & 7.12 & NA & 1,25 & 12.95 & 0.001 \\
\hline Month (M) & 1,25 & 85.22 & NA & 1,27 & 38.52 & NA & 1,26 & 40.1 & NA & 1,25 & 3.81 & 0.06 \\
\hline $\mathrm{P} \times \mathrm{C}$ & 1,25 & 0.21 & 0.65 & 1,25 & 0.01 & 0.92 & 1,25 & 0.08 & 0.77 & 1,23 & 0.81 & 0.38 \\
\hline $\mathrm{C} \times \mathrm{M}$ & 1,25 & 4.60 & 0.04 & 1,26 & 0.16 & 0.69 & 1,26 & 7.21 & 0.01 & 1,24 & 0.95 & 0.34 \\
\hline $\mathrm{P} \times \mathrm{M}$ & 1,25 & 8.23 & 0.008 & 1,27 & 4.13 & 0.05 & 1,26 & 4.46 & 0.04 & 1,25 & 1.75 & 0.20 \\
\hline $\mathrm{P} \times \mathrm{C} \times \mathrm{M}^{*}$ & 1,24 & 0.23 & 0.64 & 1,24 & 0.30 & 0.59 & 1,24 & 0.14 & 0.71 & 1,22 & 0.00 & 0.97 \\
\hline \multicolumn{13}{|l|}{ First month } \\
\hline Predators (P) & 1,13 & 20.44 & $<0.001$ & 1,13 & 2.74 & 0.12 & 1,13 & 10.53 & 0.006 & & & \\
\hline Conspecifics (C) & 1,13 & 33.08 & $<0.001$ & 1,13 & 27.62 & $<0.001$ & 1,13 & 0.00 & 0.98 & & & \\
\hline $\mathrm{P} \times \mathrm{C}^{*}$ & 1,12 & $<0.01$ & 0.97 & 1,12 & 0.10 & 0.76 & 1,12 & 0.83 & 0.38 & & & \\
\hline \multicolumn{13}{|l|}{ Second month } \\
\hline Predators (P) & 1,13 & 1.45 & 0.25 & 1,13 & 1.56 & 0.23 & 1,13 & 0.98 & 0.34 & & & \\
\hline Conspecifics (C) & 1,13 & $<0.01$ & 0.96 & 1,13 & 11.92 & 0.004 & 1,13 & 7.47 & 0.02 & & & \\
\hline $\mathrm{P} \times \mathrm{C}^{*}$ & 1,12 & 0.26 & 0.62 & 1,12 & 0.20 & 0.67 & 1,12 & 0.00 & 0.95 & & & \\
\hline
\end{tabular}




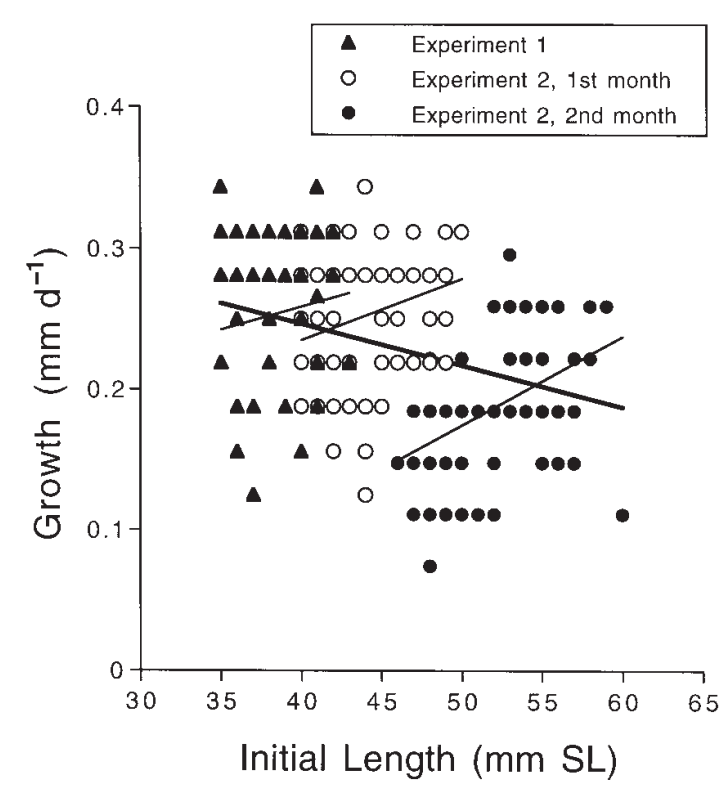

Fig. 3. Relationships between the growth of individual gobies and their length at the start of each month-long period. Narrow lines show linear fits to the data from each month and the thick line shows the fit to all data pooled. For Expt 1, $\mathrm{r}^{2}=0.015, \mathrm{p}=0.40$, and $\mathrm{n}=48$; for the first month of Expt 2 , $r^{2}=0.06, p=0.03$, and $n=83$; and for the second month of Expt 2, $\mathrm{r}^{2}=0.19, \mathrm{p}=0.00007$, and $\mathrm{n}=76$. For all data pooled, $r^{2}=0.09, p=0.00001$, and $n=207$. Fish from both predatorexposure treatments are pooled

the third month of the study were larger than in the first and second months ( $52 \pm 0.4$ vs $44 \pm 0.3 \mathrm{~mm}$ in the second month and $38 \pm 0.3 \mathrm{~mm}$ in first month), sizematched fish grew more slowly in the third month of the study than in the second (Fig. 3). Growth of sizematched fish in the first and second months, however, was similar (Fig. 3).

The magnitude of the negative effects of predators and competitors on growth rates of blackeye gobies declined across the 3 experimental periods (Figs. $1 \& 2$, Table 5) and these changes corresponded to declines in both water temperature and predator abundance. Predator abundance declined significantly across the 3 periods from $0.90( \pm 0.11)$ to $0.31( \pm 0.15)$ to 0.09 $( \pm 0.05)$ bass cage $^{-1}$ (mean $\pm 1 \mathrm{SE} ; \mathrm{n}=16$ in each case; Kruskal-Wallis test: $\mathrm{p}<0.001)$. Over the $3 \mathrm{mo}$, the average water temperature declined from $19.2( \pm 0.04)$ to $16.3( \pm 0.03)$ to $15.1( \pm 0.03){ }^{\circ} \mathrm{C}\left(\right.$ ANOVA: $F_{2,2220}=4219$, $\mathrm{p} \ll 0.00001)$.

Although the effects of both predators and competitors on growth rates declined over the 3 mo of the study, the changes did not covary perfectly and therefore the relative importance of the 2 processes differed among the 3 mo of the study. Moreover, the relative importance of the 2 processes differed among response variables, suggesting that relative importance of the 2 factors varied among individual gobies. To judge the relative importance of the 2 processes, their effects must be measured in the same units, but the effects of conspecifics were measured on a per capita basis (i.e. per additional goby), whereas the effects of predators were measured in aggregate. The effects of predators in our study cannot be expressed on a per predator basis because our estimate of predator abundance cannot be converted into a meaningful estimate of predator density. We therefore estimated the aggregate effects of competitors to compare with the aggregate effects of predators. Because the effect of intraspecific competition will depend upon the density of the focal population, for illustrative purposes, we calculated 2 estimates of the aggregate effects of competitors: the maximum and the average effects. We calculated the maximum effect as the difference between the predicted growth rate (or $\mathrm{CV}$ ) at the maximum population density found in nature, about 15 fish $\mathrm{m}^{-2}$, and at the minimum density that a goby would encounter in

Table 4. ANCOVAs testing the effects of initial size (covariate), density of conspecifics (covariate), month (categorical), and exposure to predators (categorical) on growth of individual blackeye gobies. (A) The analysis includes all 3 mo of the study, but is restricted to reefs free of predators because it was not possible to estimate accurately the effect of conspecific density on reefs exposed to predators in Expt 1 (see 'Materials and methods'), and therefore exposure to predators could not be included as a factor in the model. In (A) the factor 'month' had 3 levels, whereas in (B) it had only 2 levels. Other conventions as in Table 3. NA: not applicable

\begin{tabular}{|c|c|c|c|}
\hline Source & $\mathrm{df}$ & $F$ & $\mathrm{p}$ \\
\hline \multicolumn{4}{|c|}{ (A) Expts 1 and 2 (predator-free reefs only) } \\
\hline Size (S) & 1,116 & 1.52 & NA \\
\hline Conspecifics (C) & 1,116 & 42.66 & NA \\
\hline Month (M) & 2,116 & 33.90 & $<0.00001$ \\
\hline $\mathrm{S} \times \mathrm{C}$ & 1,116 & 33.91 & $<0.00001$ \\
\hline $\mathrm{S} \times \mathrm{M}^{*}$ & 2,114 & 1.61 & 0.20 \\
\hline $\mathrm{C} \times \mathrm{M}^{*}$ & 2,112 & 0.30 & 0.74 \\
\hline $\mathrm{S} \times \mathrm{C} \times \mathrm{M}^{*}$ & 2,110 & 0.10 & 0.90 \\
\hline \multicolumn{4}{|l|}{ (B) Expt 2} \\
\hline Size (S) & 1,152 & 0.54 & NA \\
\hline Conspecifics (C) & 1,152 & 29.70 & NA \\
\hline Predators (P) & 1,152 & 0.24 & NA \\
\hline Month (M) & 1,152 & 101.32 & NA \\
\hline $\mathrm{S} \times \mathrm{C}$ & 1,152 & 27.30 & $<0.00001$ \\
\hline $\mathrm{P} \times \mathrm{M}$ & 1,152 & 13.80 & 0.0003 \\
\hline $\mathrm{S} \times \mathrm{M}^{*}$ & 1,151 & 1.69 & 0.20 \\
\hline $\mathrm{S} \times \mathrm{P}^{*}$ & 1,150 & 0.98 & 0.32 \\
\hline $\mathrm{C} \times \mathrm{P}^{*}$ & 1,149 & 0.18 & 0.67 \\
\hline $\mathrm{C} \times \mathrm{M}^{*}$ & 1,148 & 0.06 & 0.80 \\
\hline $\mathrm{S} \times \mathrm{M} \times \mathrm{P}^{*}$ & 1,147 & 0.63 & 0.43 \\
\hline $\mathrm{S} \times \mathrm{C} \times \mathrm{P}^{*}$ & 1,146 & 0.03 & 0.85 \\
\hline $\mathrm{C} \times \mathrm{P} \times \mathrm{M}^{*}$ & 1,145 & 0.15 & 0.70 \\
\hline $\mathrm{S} \times \mathrm{C} \times \mathrm{M}^{*}$ & 1,144 & 0.04 & 0.84 \\
\hline $\mathrm{S} \times \mathrm{C} \times \mathrm{M} \times \mathrm{P}^{*}$ & 1,143 & 1.41 & 0.24 \\
\hline
\end{tabular}



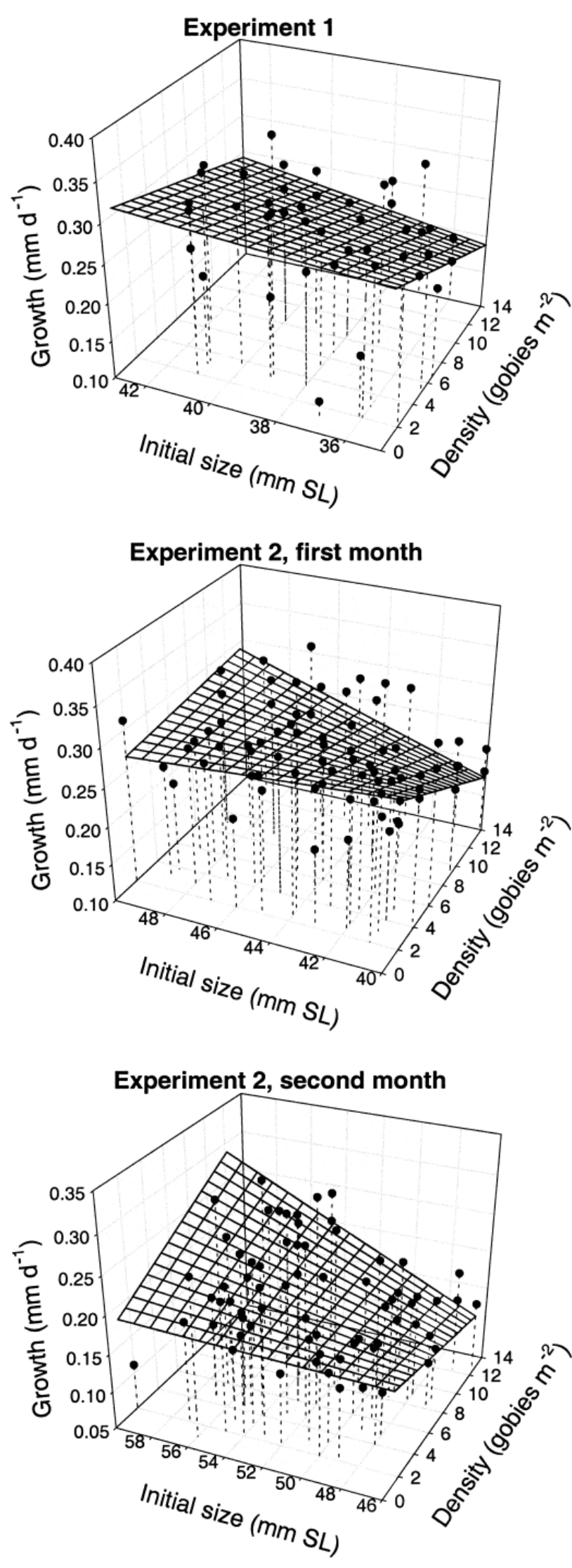

nature, 1 fish $\mathrm{m}^{-2}$ (i.e. one fish alone in a $1 \mathrm{~m}^{2}$ home range). The average effect was calculated as the difference in the predicted growth rates or $\mathrm{CV}$ at the minimum population density of 1 goby $\mathrm{m}^{-2}$ and at the average population density found in nature, about 3 gobies $\mathrm{m}^{-2}$.

Comparing the maximum aggregate effects of competitors with the effects of predators on mean growth, competitors and predators were about equally important in the first month of the study, competitors more important than predators in the second month (even though competition itself was weaker, i.e. a smaller per capita effect of conspecifics), and neither factor was important in the third month (Table 5). Examining minimum growth, the maximum aggregate effects of competition were always more important than those of predators. In contrast, examining maximum growth, the effects of predators were larger than the maximum aggregate effects of competitors in the first 2 mo of the study, but not in the third month when 'competitors' had significant positive effects on maximum growth

Comparing average aggregate effects of competitors with those of predators on mean, minimum, and maximum growth, predators were more important than competitors in the first 2 mo of the study. In the third month of the study neither predators nor competitors were important in influencing mean growth, but competitors were more important in affecting minimum and maximum growth than predators (which had no significant effects). Competitors always had a stronger effect on growth variability (CV) than predators did since predators never significantly influenced this response variable and competitors did. In general, the negative effects of predators on growth rates were greater than those of competitors for fast growing fish (maximum growth), whereas the effects of competitors were generally more important than those of predators for slow growing fish (minimum growth). For all 3 growth rate response variables, the largest relative effects of predators occurred during Expt 1, when predators were most abundant.

Fig. 4. Interactive effects of size and population density on individual growth of blackeye gobies (see Table 4 for statistics), presented for each month of the study. Population density was measured as the daily average per reef integrated over each month. Each point represents growth of one fish and fish from both predator-exposure treatments are pooled. This pooling causes some extra scatter of points, but does not confound the interpretation of the plots since the effect of predators did not interact with those of size and density (Table 4). For Expt 1, Expt 2, first month, and Expt 2, second month, $\mathrm{n}=48,83$, and 76 , respectively 


\section{DISCUSSION}

We found that predators reduced the growth of blackeye gobies during much of our study. Prey often grow more slowly in the presence of predators in other systems (e.g. Werner et al. 1983, Semlitsch 1987, Skelly \& Werner 1990, Fraser \& Gilliam 1992, Peckarsky et al. 1993, Scrimgeour \& Culp 1994), but few studies have explored this phenomenon in marine animals. The few published studies that have tested for predatorinduced reductions in growth of marine animals have found them (Connell 1998, Steele 1998, Nakaoka 2000, this study). Furthermore, marine animals are well known to alter their foraging behavior in response to predators (e.g. Holbrook \& Schmitt 1988, Irlandi \& Peterson 1991, Micheli 1997, Steele 1998), so we suspect that sublethal effects of predators on prey growth may be widespread in marine systems. Certainly, such effects merit greater attention in marine systems than they have received to date.

Typically, sublethal effects of predators on the growth of their animal prey are caused by a shift in the behavior of prey in the presence of predators. One common response of prey to predators is to reduce their rate of foraging (and movement in general) to reduce their risk of being detected (reviewed in Lima \& Dill 1990). Blackeye gobies reduce their rate of foraging by 10-fold when predators are near them (Steele 1998) and this behavioral response probably caused the reduced growth of individuals exposed to predators in this study. Prey growth can also be reduced by predators by other mechanisms, e.g. by relocating foraging to safer microhabitats that contain less or poorer quality food (Werner et al. 1983) or by nonlethal damage caused by predators (Peterson \& Quammen 1982). Neither of these mechanisms is likely in our study system because there was no alternative microhabitat available to the gobies and, when detected by predators, the gobies are either consumed whole or escape without injury (M. Steele pers. obs.).

Sublethal effects on prey growth may have important demographic consequences for prey populations because of the functional relationships between size, maturity and fecundity, and between size and risk of mortality (Werner \& Gilliam 1984, Heintz et al. 2000). In fishes and many other organisms, maturity and fecundity are directly related to body size (Bagenal 1978, Wootton 1979, Peterson 1983, Werner \& Gilliam 1984, Jones 1987, Levitan 1989), and therefore, the effects of predators on growth may ultimately reduce reproductive output. Also, in sex-changing species, like the blackeye goby, effects on growth rates may further alter reproductive output by modifying the sex ratio of the population. Additionally, effects on growth may alter rates of mortality if it is a function of size. Most predators are size selective, so size-related mortality may be widespread (see e.g. review by Sogard 1997), but the issue of size-related risk of predation is a complex one that has received inadequate attention in natural settings (vs the laboratory). It is made complex by the fact that most prey species are exposed to a wide variety of predators that may show both positive and negative size selectivity that will vary with their own size (Werner \& Gilliam 1984). We have found no evidence that risk of predation changes with size in blackeye gobies, either in the present study or other field experiments (Steele 1995, Steele unpubl.).

In addition to predatory effects, we also found significant effects of intraspecific competition on growth of blackeye gobies in our study. Effects of intraspecific compe- 
tition on growth are well known in reef fishes (e.g. Doherty 1983, Jones 1987, Forrester 1990, Booth 1995, Steele 1998) and are thought to be caused by both exploitative and interference competition for food (Forrester 1990, Jones 1991), though social limitation of growth in the absence of food limitation (e.g. Abbott \& Dill 1989) is also an untested possibility. Our findings that small fish grew more slowly than large fish in dense populations but not in sparse ones, and that the negative effects of competition were greater for small than large fish (Fig. 4), suggest that interference competition mediated via size-based dominance hierarchies (i.e. asymmetric competition) played an important role in generating the intraspecific competition detected in this study. This notion is also supported by the increasing variability (CV) of growth with population density (growth depensation sensu Magnuson 1962) and the demonstration that minimum growth in populations was much more strongly affected by population density than maximum growth. Intriguingly, in the final month of our study, large, fast-growing individuals actually benefited from enhanced population densities, with their growth increasing with population density, whereas small, slow-growing fish suffered negatively density-dependent growth (Figs. 2 \& 4). This finding is also consistent with size-based dominance hierarchies, but the mechanism driving positive effects of density on large fish is unknown. Dominance hierarchies based on size and consequent individual variation in effects of competition are common in fishes (e.g. Magnuson 1962, Rubenstein 1981, Forrester 1991) and congruent with Cole (1984) and Breitburg's (1987) observations of size-based dominance hierarchies in blackeye gobies and with Steele's (1995) finding that agonistic interactions increase disproportionately with population density in this species.

Many animals have social systems that generate individual-level variation in the effects of competition and by exploring only average effects, as is most commonly done, we may fail to grasp the actual consequences and importance of competition in nature (Rubenstein 1981). For example, if we had only examined the effects of competition on average growth rates, we would have failed to recognize that the relative importance of competition and sublethal effects of predators depends on size, with predatory effects being more important for large, fast-growing individuals than for small, slow-growing individuals. This finding is contrary to the widespread expectation that the effects of predators should fall most heavily on small individuals, which are thought face the highest risk of predation (Sogard 1997). But as noted earlier, we have found no evidence that risk of predation changes with size in the blackeye goby. Nevertheless, the relative importance of sublethal effects of predators and com- petitors did vary with size during the present study, and hence, we reiterate the point that it will be extremely important to incorporate size-based variation in the effects of competition and predation into models of population and community dynamics (Werner \& Gilliam 1984).

Over the course of this study, the strength of competition declined. We suspect that this decline was caused by seasonal changes in temperature and food abundance. Declines in water temperature should have caused the metabolic rates of the gobies to slow, which lowers maximal growth rates and the amount of food required to achieve them (Brett 1979). Because of this effect of water temperature on metabolic rates, food should have limited growth most strongly when the water was warmest (July) and least when it was coldest (November/December). Roughly equivalent rates of growth in July and October/November, despite significantly cooler water during the later period, may have been driven by increased food availability in fall (unfortunately we have no data on this). Average size of the gobies increased across the 3 mo, but we think it unlikely that this typical seasonal change can account for the decline in the strength of competition over our study, since the larger fish in last month of our study should have had higher metabolic requirements than smaller fish earlier. By that logic, competition should have increased across the 3 mo, rather than decreased.

The magnitude of sublethal effects of predators on growth also declined over the course of the study and this mirrored predictable seasonal declines in predator abundance and water temperature, and increases in the average size of individual gobies. Presumably, as the abundance of predators declined, the inhibitory effects of predators on blackeye goby foraging should have declined, resulting in a smaller predatory effect on growth rates. The decline in predator abundance from summer to winter is a normal occurrence at Santa Catalina Island (M. Steele pers. obs.) and our impression is that it is caused by a redistribution from shallow to deeper areas and not from an actual change in overall abundance of kelp and sand bass. The inhibitory effect of predators on growth may also have declined over the period of our study if the gobies were more willing to forage in the presence of predators as they grew larger over the course of the study. This might have occurred if the gobies perceived their risk of predation to decline with increasing size. Although we cannot rule out this possibility, and it may well be important in other species, it seems unlikely in the blackeye goby since we have found no evidence that predation risk varies with size in this species (this study, Steele 1995, Steele unpubl.). Finally, the magnitude of predatory effects on growth may have declined over the course of the study because cooling water 
temperatures should have lowered proportion of time that predator-caused reductions in foraging caused food intake to drop below growth-limiting levels, due to temperature-mediated declines in the rate of metabolism.

Predictable seasonal variation in water temperature, predator abundance, goby population size structure, and food availability likely caused the magnitude of predatory and competitive effects, and their relative importance, to differ among the 3 mo of this study. Such seasonal changes are the rule in most systems, even tropical ones, though the range of variability will be reduced in the tropics. Hence, we expect the relative importance of competition and predation to shift continually in marine systems due to seasonal and ontogenetic changes. Our results suggest that we may be able to predict these shifts by measuring a few simple variables like water temperature, predator abundance, food abundance, and prey-population size structure.

Acknowledgements. We thank S. Anderson, B. Fredericks, J. Malone, Y. Springer, and T. Trejo for excellent assistance in the field, and the staff of the Wrigley Institute for Environmental Studies for outstanding logistical assistance. The manuscript was improved by the comments of C. Peterson and 3 anonymous reviewers. This work was supported by a grant from the National Science Foundation to G.E.F. (OCE 9618011/0096061) and a traineeship from the U.C. Coastal Toxicology program to M.A.S. This is contribution number 217 from the Wrigley Institute for Environmental Studies.

\section{LITERATURE CITED}

Abbott JC, Dill LM (1989) The relative growth of dominant and subordinate juvenile steelhead trout (Salmo gairdneri) fed equal rations. Behaviour 108:104-113

Bagenal TB (1978) Aspects of fish fecundity. In: Gerking SD (ed) Ecology of freshwater fish production. Wiley, New York, p 75-101

Beal BF, Parker MR, Vencile KW (2001) Seasonal effects of intraspecific density and predator exclusion along a shorelevel gradient on survival and growth of juveniles of the soft-shell clam, Mya arenaria L., in Maine, USA. J Exp Mar Biol Ecol 264:133-169

Bertness MD (1989) Intraspecific competition and facilitation in a northern acorn barnacle population. Ecology 70 257-268

Booth DJ (1995) Juvenile groups in a coral-reef damselfish: density-dependent effects on individual fitness and population demography. Ecology 76:91-106

Breitburg DL (1987) Interspecific competition and the abundance of nest sites: factors affecting sexual selection. Ecology 68:1844-1855

Brett JR (1979) Environmental factors and growth. In: Hoar WS, Randall DJ, Brett JR (eds) Fish physiology, Vol VIII Bioenergetics and growth. Academic Press, New York, p 599-675

Cole KS (1982) Male reproductive behaviour and spawning success in a temperate zone goby, Coryphopterus nicholsi. Can J Zool 60:2309-2316
Cole KS (1983) Protogynous hermaphroditism in a temperate zone territorial marine goby, Coryphopterus nicholsi. Copeia 1983:809-812

Cole KS (1984) Social spacing in the temperate marine goby Coryphopterus nicholsi. Mar Biol 80:307-314

Connell SD (1998) Effects of predators on growth, mortality and abundance of a juvenile reef-fish: evidence from manipulations of predator and prey abundance. Mar Ecol Prog Ser 169:251-261

Dayton PK (1971) Competition, disturbance, and community organization: the provision and subsequent utilization of space in a rocky intertidal community. Ecol Monogr 41: 351-389

Doherty PJ (1983) Tropical territorial damselfishes: is density limited by aggression or recruitment? Ecology 64:176-190

Fairweather PG, Underwood AJ, Moran MJ (1984) Preliminary investigations of predation by the whelk Morula marginalba. Mar Ecol Prog Ser 17:143-156

Forrester GE (1990) Factors influencing the juvenile demography of a coral reef fish. Ecology 71:1666-1681

Forrester GE (1991) Social rank, individual size and group composition as determinants of food consumption by humbug damselfish, Dascyllus aruanus. Anim Behav 42: $701-711$

Forrester GE, Steele MA (2000) Variation in the presence and cause of density-dependent mortality in three species of reef fishes. Ecology 81:2416-2427

Fraser DF, Gilliam JF (1992) Nonlethal impacts of predator invasion: facultative suppression of growth and reproduction. Ecology 73:959-970

Heintz RA, Rice SD, Wertheimer AC, Bradshaw RF, Thrower FP, Joyce JE, Short JW (2000) Delayed effects on growth and marine survival of pink salmon Oncorhynchus gorbuscha after exposure to crude oil during embryonic development. Mar Ecol Prog Ser 208:205-216

Hixon MA, Carr MH (1997) Synergistic predation, density dependence, and population regulation in marine fish. Science 277:946-949

Holbrook SJ, Schmitt RJ (1988) The combined effects of predation risk and food reward on patch selection. Ecology 69:125-134

Irlandi EA, Peterson CH (1991) Modification of animal habitat by large plants: mechanisms by which seagrasses influence clam growth. Oecologia 87:307-318

Jones GP (1987) Competitive interactions among adults and juveniles in a coral reef fish. Ecology 68:1534-1547

Jones GP (1991) Postrecruitment processes in the ecology of coral reef fish populations: a multifactorial perspective. In: Sale PF (ed) The ecology of fish on coral reefs. Academic Press, San Diego, CA, p 294-330

Krebs CJ (1994) Ecology: the experimental analysis of distribution and abundance, 4th edn. Harper Collins College Publishers, Menlo Park, CA

Levitan DR (1988) Density-dependent size regulation and negative growth in the sea urchin Diadema antillarum Philippi. Oecologia 76:627-629

Levitan DR (1989) Density-dependent size regulation in Diadema antillarum: effects on fecundity and survivorship. Ecology 70:1414-1424

Lima SL, Dill LM (1990) Behavioral decisions made under risk of predation: a review and prospectus. Can J Zool 68: $619-640$

Magnuson JJ (1962) An analysis of aggressive behavior, growth, and competition for food and space in medaka (Oryzias latipes (Pisces, Cyprinodontidae)). Can J Zool 40: 313-363

McPeek MA, Peckarsky BL (1998) Life histories and the 
strengths of species interactions: combining mortality, growth and fecundity effects. Ecology 79:867-879

Menge BA (1983) Components of predation intensity in the low zone of the New England rocky intertidal region. Oecologia 58:141-155

Micheli F (1997) Effects of predator foraging behavior on patterns of prey mortality in marine soft bottoms. Ecol Monogr 67:203-224

Miller DJ, Lea RN (1976) Guide to the coastal fishes of California. Calif Fish Game 157:1-249

Nakaoka M (2000) Nonlethal effects of predators on prey populations: predator-mediated change in bivalve growth. Ecology 81:1031-1045

Peckarsky BL, Cowan CA, Penton MA, Anderson CR (1993) Sublethal consequences of stream-dwelling predatory stoneflies on mayfly growth and fecundity. Ecology 74:1836-1846

Peterman RM (1984) Density-dependent growth in early ocean life of sockeye salmon Oncorhynchus nerka. Can J Fish Aquat Sci 41:1825-1829

Peterson CH (1983) Quantitative allometry of gamete production by Mercenaria mercenaria into old age. Mar Ecol Prog Ser 29:93-97

Peterson CH, Quammen ML (1982) Siphon nipping: its importance to small fishes and its impact on growth of the bivalve Protothaca staminea (Conrad). J Exp Mar Biol Ecol 63:249-268

Rubenstein DI (1981) Individual variation and competition in the Everglades pygmy sunfish. J Anim Ecol 50:337-350

Sano M (1997) Temporal variation in density dependence: Recruitment and postrecruitment demography of a temperate zone sand goby. J Exp Mar Biol Ecol 214:67-84

Schmitt RJ, Holbrook SJ (1999) Mortality of juvenile damselfish: implications for assessing processes that determine abundance. Ecology 80:35-50

Schmitt RJ, Holbrook SJ, Osenberg CW (1999) Quantifying the effects of multiple processes on local abundance: a cohort approach for open populations. Ecol Lett 2: 294-303

Scrimgeour GJ, Culp JM (1994) Feeding while evading predators by a lotic mayfly: linking short-term foraging behaviors to long-term fitness consequences. Oecologia 100:128-134

Semlitsch RD (1987) Interactions between fish and salamander larvae: costs of predator avoidance or competition? Oecologia 72:481-486

Shima JS (1999) Variability in relative importance of determinants of reef fish recruitment. Ecol Lett 2:304-310

Skelly DK, Werner EE (1990) Behavioral and life-historical responses of larval American toads to an odonate predator. Ecology 71:2313-2322

Editorial responsibility: Charles Peterson (Contributing Editor), Morehead City, North Carolina, USA
Sogard, SM (1997) Size-selective mortality in the juvenile stage of teleost fishes: a review. Bull Mar Sci 60: 1129-1157

Steele MA (1995) The contributions of predation, competition, and recruitment to population regulation of two temperate reef fishes. PhD dissertation, University of California, Santa Barbara

Steele MA (1996) Effects of predators on reef fishes: separating cage artifacts from effects of predation. J Exp Mar Biol Ecol 198:249-267

Steele MA (1997) The relative importance of processes affecting recruitment of two temperate reef fishes. Ecology 78: 129-145

Steele MA (1998) The relative importance of predation and competition in two reef fishes. Oecologia 115:222-232

Steele MA (1999) Effects of shelter and predators on reef fishes. J Exp Mar Biol Ecol 233:65-79

Stoner AW (1989) Density-dependent growth and grazing effects of juvenile queen conch Strombus gigas L. in a tropical seagrass meadow. J Exp Mar Biol Ecol 130: 119-134

Underwood AJ (1984) Vertical and seasonal patterns in competition for microalgae between intertidal gastropods. Oecologia 64:211-222

Underwood AJ (1997) Experiments in ecology: their logical design and interpretation using analysis of variance. Cambridge University Press, Cambridge

Vincent B, Joly D, Harvey M (1994) Spatial variation in growth of the bivalve Macoma balthica (L.) on a tidal flat: effects of environmental factors and intraspecific competition. J Exp Mar Biol Ecol 181:223-238

Welden CW, Slauson WL (1986) The intensity of competition versus its importance: an overlooked distinction and some implications. Q Rev Biol 61:23-44

Werner EE, Gilliam JF (1984) The ontogenetic niche and species interactions in size-structured populations. Annu Rev Ecol Syst 15:393-425

Werner EE, Gilliam JF, Hall DJ, Mittelbach GG (1983) An experimental test of the effects of predation risk on habitat use in fish. Ecology 64:1540-1548

Wiley JW (1973) Life history of the western North American goby, Coryphopterus nicholsii (Bean). Proc S Diego Soc Nat Hist 17:187-208

Wilkinson L, Hill M, Vang E (1992) SYSTAT: Statistics, Version 5.2 edn. SYSTAT Inc., Evanston, IL

Wissinger SA (1989) Seasonal variation in the intensity of competition and predation among dragonfly larvae. Ecology 70:1017-1027

Wootton RJ (1979) Energy costs of egg production and environmental determinants of fecundity in teleost fishes. Proc Zool Soc Lond 44:133-159

Submitted: January 11, 2001; Accepted: February 22, 2002

Proofs received from author(s): May 21, 2002 